\title{
Imágenes de Madrid durante el Siglo de Oro: pintura y literatura como huellas del palimpsesto urbano
}

\section{Images of Madrid during Golden Age: Painting and Literature Like Traces of the Urban Palimpsest}

\section{Jesús Ángel Sánchez Rivera}

Universidad Complutense de Madrid ESPAÑA

jasanchezrivera@ucm.es

[Hipogrifo, (issn: 2328-1308), 8.2, 2020, pp. 193-213]

Recibido: 06-04-2020 / Aceptado: 17-04-2020

DOI: http://dx.doi.org/10.13035/H.2020.08.02.13

Resumen. La decisión de Felipe II de establecer la Corte en la Villa de Madrid en 1561 resultaría a la postre un hecho de enorme trascendencia para esta población ubicada en el centro de la Península Ibérica, que devendría, pasados los siglos, en su actual condición de capital. Este trabajo ofrece una compilación crítica de ciertas creaciones artísticas (obras pictóricas y literarias) realizadas durante el Siglo de Oro de la cultura española, para comprender mejor cómo se gestó y desarrolló la imagen urbana de Madrid en aquel tiempo. Las obras referidas contribuyeron, sin duda, a crear un imaginario colectivo propio de la Villa y Corte, que aún hoy se puede rastrear en el formidable palimpsesto madrileño.

Palabras clave. Siglo de Oro; Madrid; Pintura; Literatura; interdisciplinariedad.

Abstract. The decision of Felipe II to establish the Court in the Villa of Madrid in 1561 would ultimately result in a fact of enormous importance for this population located in the center of the Iberian Peninsula, which would become, over the centuries, in its current condition as capital. This article offers a critical compilation of certain artistic creations (pictorial and literary works) made during the Golden Age of Spanish culture, to better understand how the urban image of Madrid was 
conceived and developed at that time. The aforementioned works undoubtedly contributed to creating a collective imagery typical of the Villa y Corte, which can still be traced today in Madrid's formidable palimpsest.

Keywords. Golden Age; Madrid; Painting; Literature; interdisciplinarity.

Para ver un lugar es preciso volver a verlo.

(Claudio Magris)

La ciudad está prisionera en las palabras.

[...] está prisionera en la memoria.

(Fernando Pessoa)

\section{INTRODUCCIÓN}

Partiendo del tópico que conceptualiza la ciudad como un colosal palimpsesto en el que es posible rastrear y descifrar buena parte de su pasado, el presente trabajo trata de ofrecer una síntesis elocuente y esencial de ciertos vestigios de Madrid creados a lo largo del llamado Siglo de Oro -o Siglos de Oro- de la cultura española. Nos referimos a las representaciones de la urbe en la pintura y en la literatura de este período entendido en sentido amplio, es decir, el comprendido entre los reinados de Felipe II (1527/1556-1598) y Carlos II (1661/1665-1700), último monarca de los Austrias españoles. Imágenes pintadas e imágenes escritas que contribuyeron, sin duda, a crear un imaginario colectivo idiosincrásico de la Villa y Corte. Sobre estos fundamentos se fueron construyendo nuevos discursos que, hasta nuestros días, han enriquecido y vivificado múltiples lecturas sobre el palimpsesto madrileño.

La pintura de vistas urbanas evidencia la elección de ciertos lugares que, generación tras generación, se han convertido en puntos singulares y significativos entre el conjunto de informaciones que conforman el imaginario colectivo e individual de la ciudad. Corresponderían a aquellos que Kevin Lynch denominó «puntos focales clave» ${ }^{1}$. La percepción de estos lugares por parte de los literatos del Siglo de Oro constituye, a nuestro entender, un elemento de extraordinario valor que enriquece y complementa significativamente aquellas imágenes pictóricas ${ }^{2}$. Además, la estrecha y nutricia relación que existió entre literatura y pintura durante aquella época justifica por sí misma el planteamiento de este trabajo, que pretende un enfoque interdisciplinar. Su engarce con el estudio crítico de otras fuentes históricas de carácter gráfico (dibujos, estampas, planos...) y escrito (documentación, cronística, literatura de viajes...) permitirá, sin duda, una aproximación más completa a la cultura aurisecular de Madrid.

1. Lynch, 2015, p. 107.

2. Sobre la relación entre el espacio urbano madrileño y la literatura en el Seiscientos: García SantoTomás, 2004. 
El conocimiento de la ciudad pasa necesariamente por su conocimiento histórico. «El método histórico parece ser aquel capaz de ofrecernos la verificación más segura de cualquier hipótesis sobre la ciudad, que en sí misma es depositaria de la historia», escribió Rossi ${ }^{3}$. Y las representaciones pintadas o escritas de las ciudades, en tanto que fuentes históricas, ofrecen imágenes muy vívidas, atractivas y elocuentes sobre su pasado, a la vez que son ciertamente reveladoras - si bien esto entraña una dificultad interpretativa añadida- sobre su presente.

\section{PINTAR CON LAS PALABRAS, DESCRIBIR CON LOS PINCELES: MADRID, VILLA Y CORTE}

\subsection{Entre el Alcázar y el Buen Retiro}

En 1561, la decisión de Felipe II de establecer de manera definitiva la Corte en Madrid -con excepción del período en que se trasladó a Valladolid, 1601-1606, ya bajo el reinado de su hijo- resultó, a la postre, trascendental para esta mediana villa situada, muy oportunamente, en el centro peninsular. El Monarca, inspirado por la tradición clásica y su revitalización renacentista, halló en Madrid el lugar idóneo, rodeándolo de otros Sitios Reales que conformaron una trama acorde a su proyecto cortesano ${ }^{4}$. Desde aquel momento, próximo a la colocación de la primera piedra de la magna construcción del Monasterio de San Lorenzo el Real en El Escorial (1563), obra emblemática y totalizadora del reinado filipino, y a la última sesión del largo Concilio de Trento (3 y 4 de diciembre de 1563), la villa castellana fue transformando su ser, renovado al calor de la Reforma católica y de la incipiente cultura del Barroco.

Al tiempo que se acometían las reformas necesarias en el Alcázar madrileño, que ya bajo el reinado de Carlos $\vee$ se había transformado notablemente con la intervención de Alonso de Covarrubias ${ }^{5}$, iban arribando numerosos miembros de la nobleza y del clero, embajadas e infinidad de gentes dispuestas a medrar en la nueva urbe cortesana. Era necesario crear una imagen renovada de la antigua Villa, una imagen digna, decorosa, que proyectara el poder del Monarca cuyos dominios se extendían por todo el orbe.

No es casual que una de las primeras vistas de Madrid realizadas por Antoon van den Wijngaerde (castellanizado, Antonio de las Viñas) se feche hacia 1562, al año siguiente de que la villa obtuviera el honor de su designación como sede cortesana -y de que el artista llegase a España llamado por Felipe II-. Se trata de la Vista de Madrid (Österreichische Nationalbibliothek, Viena). De hacia 1568 es un segundo dibujo de El Alcázar de Madrid conservado en la misma institución, en el 
que se muestra sólo el Alcázar desde su ángulo suroriental (fig. 1)6. Por su importancia documental y su singularidad serán las únicas obras seleccionadas que no son estrictamente pinturas, sino dibujos - si bien coloreados-. Abundan las vistas urbanas de Madrid en otros soportes y técnicas (dibujos, estampas, etc.), aunque de los siglos XVI y XVII no hallamos tantos ejemplos si los comparamos con las vistas de otras ciudades europeas - piénsese en Roma o París-. Pero este no es el objeto de este ensayo.

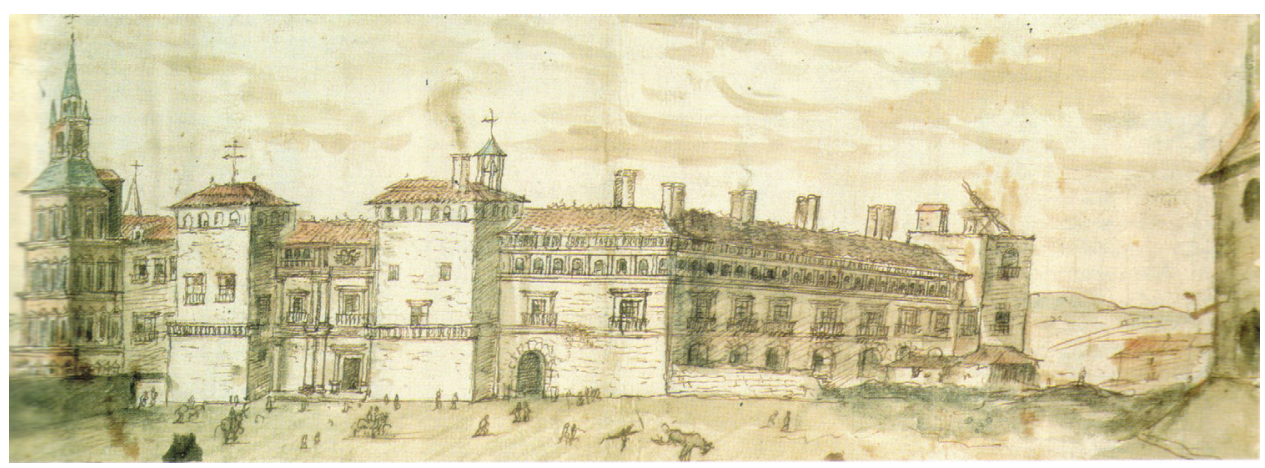

Fig. 1. Antoon van den Wijngaerde. El Alcázar de Madrid, h. 1568

(Österreichische Nationalbibliothek, Viena)

La orografía sobre la que se estableció el antiguo Maherit musulmán condicionaría inevitablemente el modo de mirar la población desde la distancia. El estratégico emplazamiento de la alcazaba en un altozano, sobre las terrazas fluviales del que más tarde se llamaría río Manzanares, privilegió la visión de la población desde la otra orilla del río, desde lo que luego se convertiría en el Real Sitio de la Casa de Campo, en la parte occidental -que entonces ofrecía un punto de vista inmejorable de su centro de poder-.

El primero de los dibujos de Wijngaerde plantea una vista en perspectiva de Madrid desde fuera, a cierta distancia, con el fin de abarcar la urbe por completo. Domina la mole del antiguo Alcázar, localizado en el punto más elevado?. También destaca la muralla medieval, jalonada por numerosos torreones defensivos, y sobresalen, entre el caserío, las torres de las iglesias parroquiales. Wijngaerde da muestras de una gran precisión descriptiva, tanto en los aspectos topográficos como en la morosa plasmación de los elementos arquitectónicos más relevantes. Por otra parte, sería el primero en ofrecer una visión perspectiva de lo que más tarde se denominara «cornisa» de Madrid, un término ligado al concepto de «paisaje de aproximación» de la urbe ${ }^{8}$.

6. Ambos pertenecen a un álbum de 79 dedicado a las ciudades españolas; Galera i Monegal, 1998, pp. 112, ÖB. 45, y 118, ÖB. 63.

7. Empleamos la clasificación tipológica de De Seta, 2016, p. 2.

8. Rodríguez Romero, 2018. 
En el segundo dibujo, por ejemplo, se puede ver con detalle la Torre Dorada, cuya construcción se inició al poco de instalarse la Corte, acometiéndose entre 1561 y 1566; en este espacio, probablemente ideado por Gaspar de Vega, Felipe II instaló su despacho. Asimismo, se advierten las intervenciones realizadas por Covarrubias en la fachada meridional unas décadas antes.

Los dibujos del flamenco hubieron de servir como modelos para obras grabadas o pintadas que tendrían como núcleo polarizador de la atención el antiguo Alcázar, construcción que condensaba la imagen cortesana de la villa castellana. De este modo, podemos citar el lienzo de Alonso Sánchez Coello, retrato de las Infantas Isabel Clara Eugenia y doña Catalina Micaela, h. 1568-1569 (Patrimonio Nacional, Convento de las Descalzas Reales de Madrid), en el que aparece una representación del Alcázar muy similar al segundo dibujo referido. Desde un punto de vista más alejado, desde la margen occidental del río, también mencionaremos la Vista del Alcázar de Madrid, h. 1615-1651 (Museo de la Ciudad de Madrid), pintada por Félix Castello, en la que se pueden identificar otros edificios desaparecidos, como la iglesia de Nuestra Señora de la Almudena, y monumentos aún en pie, como el puente de Segovia. Habitualmente, estas pinturas se idearon como series de cuadros para mostrar las posesiones más preciadas y representativas de una determinada casa real o nobiliaria. Esta plasmación visual de los dominios fue frecuente en las decoraciones interiores de algunos palacios urbanos y suburbanos desde el Renacimiento.

La fachada meridional del Alcázar fue, desde antiguo, el acceso principal al edificio, y por ello siempre se le prestó especial atención; sin duda, su carácter preeminente, y el ser concebida, además, como una suerte de gran fondo escénico de la plaza situada frente a él, condicionó la perspectiva adoptada de la mayoría de las imágenes habidas del edificio, desaparecido, como bien es sabido, a consecuencia del incendio que sufriera en la Nochebuena de 1734. Al segundo de los dibujos conservados de Wijngaerde y a la representación de Sánchez Coello, podemos añadir otro tipo de fuentes artísticas que permiten su mejor conocimiento. El Modelo de la fachada principal del Alcázar de Madrid, h. 1630-1646 (Museo de la Ciudad de Madrid), atribuido en ocasiones a Giovanni Battista Crescenzi, ofrece un testimonio tridimensional de la reforma que se acometió en la primera mitad del Seiscientos ${ }^{9}$. Sería la imagen más repetida -insistimos- del edificio, como se puede ver en un grabado de Louis Meunier, Fachada del Alcázar de Madrid (1666) o en la pintura Vista del cortejo de Carlos II en el Alcázar, 1677 (Colección Abelló, Madrid) ${ }^{10}$, que aporta una representación del ceremonial cortesano en la plaza de Palacio y el detalle de la colocación temporal que tuvo el Retrato ecuestre de Felipe IV rematando la fachada.

Entre los numerosos testimonios escritos que dejaron cronistas, literatos y viajeros, podemos citar el que dejara el humanista Juan López de Hoyos en recuerdo del recibimiento de la reina Ana de Austria (1570), la prolija descripción del cronista Gil González Dávila (1623), la mención que hiciera Jerónimo de Quintana (1629) 
-en la que alaba sus privilegiadas vistas, «deleitosos jardines» y «el Parque lleno de caza» - o las impresiones de Madame d'Aulnoy (1691), siempre jugosas por su mirada literaria ${ }^{11}$.

Por otra parte, en las vistas urbanas tomadas desde el lado occidental suele aparecer el puente de Segovia, que mandara construir Felipe II entre 1582 y 1584 , con trazas de Juan de Herrera. Está presente en el lienzo ya aludido de Félix CasteIlo. También en la Vista desde la salida del puente de Segovia con toros desmandados, modesta obra anónima de h. 1640-1660 (Museo de la Ciudad de Madrid), que ofrece la particularidad de representar un episodio anecdótico, el de unos toros que, huidos del redil, atacan mientras son asediados por caballeros y criados (fig. 2); próxima al Campo del Moro se encontraba la Tela de justar, que en ocasiones se convertía en coso taurino ${ }^{12}$.

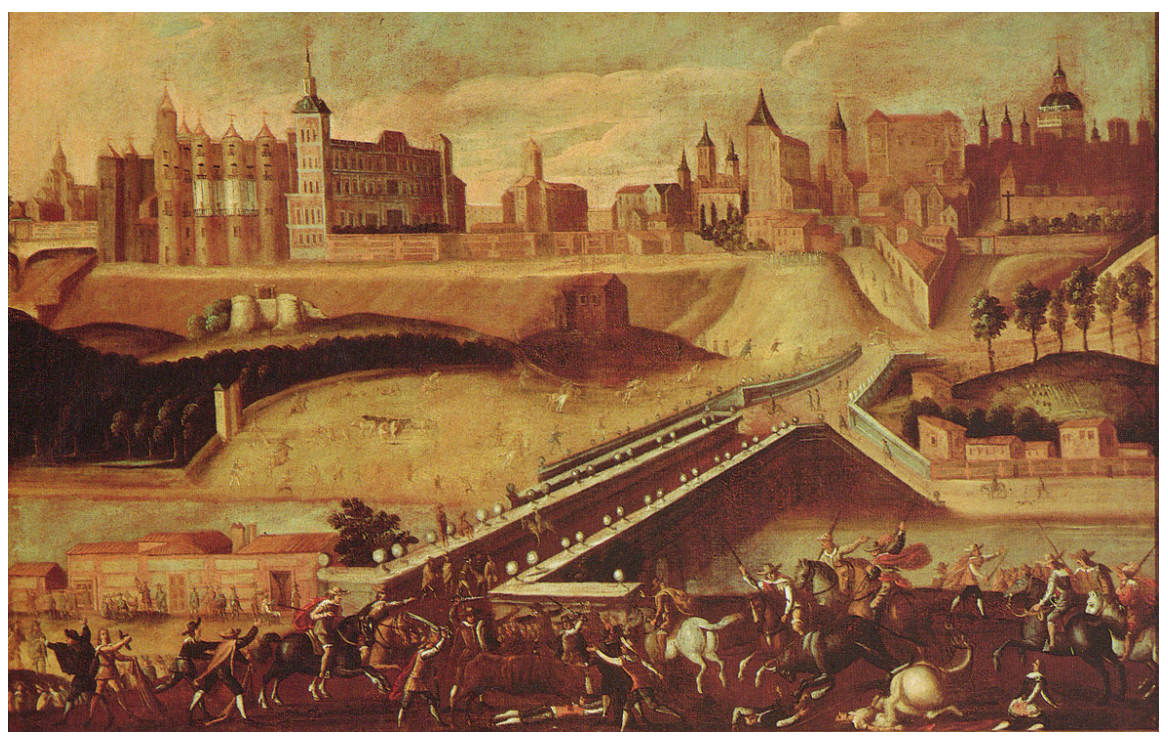

Fig. 2. Anónimo. Vista desde la salida del puente de Segovia con toros desmandados, h. 1640-1660 (Museo de la Ciudad de Madrid)

Pero, sin duda, las imágenes más elocuentes y conocidas del río Manzanares a su paso por Madrid, especialmente en el tramo del puente de Segovia, fueron creadas por las más célebres plumas del Seiscientos español. Luis de Góngora dedicaría un soneto A la puente segoviana, que está sobre el río Manzanares de Madrid (1609) ${ }^{13}$, y varios romances, haciendo sátira de su escaso caudal en relación con el enorme puente. También Francisco de Segura escribió «Al humilde Manzana-

11. Todas estas fuentes forman parte de una selección mucho más amplia publicada en El Real Alcázar de Madrid, 1994, pp. 487-509.

12. Deleito y Piñuela, 1988, p. 103.

13. Góngora, Poesía, pp. 87-88. 
res». El madrileño Lope de Vega haría lo mismo en varias composiciones ${ }^{14}$. En la misma línea, el protagonista de El Diablo Cojuelo, de Luis Vélez de Guevara, dice: «otro día le enseñaremos [...] el río Manzanares, que se llama río porque se ríe de los que van a bañarse en él, no teniendo agua» ${ }^{15}$. Y Francisco de Quevedo escribió varios romances a este «arroyo aprendiz de río» o «arroyo vergonzante» en verano, uno de los cuales comienza así:

\section{Llorando está el Manzanares, \\ al instante que lo digo, \\ por los ojos de su puente \\ pocas hebras hilo a hilo ${ }^{16}$.}

Las sátiras y parodias sobre el Manzanares proliferaron hasta convertirse en un verdadero tópico literario, que no hacía sino recoger el sentir de oriundos y foráneos, como plasmó la condesa d'Aulnoy ${ }^{17}$. Entreveradas con ellas, fueron constantes las alusiones a los personajes que pululaban en sus riberas (bañistas en los meses estivales, lavanderas, galanes, amantes, prostitutas...). La vida bullía entre las fatigas cotidianas y diversas festividades, como la romería de Santiago el Verde, que concurría en la ermita dedicada a San Felipe y Santiago, en el lugar llamado el Soto -o el Sotillo-18. De la fiesta de San Juan Bautista, existe un lienzo anónimo de particular interés, Vista del Manzanares en la fiesta de San Juan, h. 1650-1660 (Colección Abelló, Madrid) ${ }^{19}$, pues ilustra con gran detalle -aunque con escasa calidad artística - la costumbre de bañarse, comer y pasear en aquella celebración estival que mencionan los literatos. La fiesta barroca, «aunque se realice en un lugar campestre, próximo o relacionado con la ciudad, conforme imaginan Tirso o Céspedes, supone, en cualquier caso, la conexión con el medio urbano» ${ }^{20}$. Asimismo, el reverso delictivo, sórdido y violento de aquellas celebraciones ya fue puesto de manifiesto en numerosos escritos de la época, entre los que destaca la obra de Bautista Remiro de Navarra, significativamente titulada Los peligros de Madrid (1646)21.

Entre el espacio originario de la villa y su extremo oriental, se estableció un eje viario, la calle Mayor, convertida en una arteria fundamental para la vida social. Así lo recoge, por ejemplo, Vélez de Guevara, que lo denomina «insigne paseo» en las horas vespertinas, donde «tantas figuras [...] en aquel teatro del mundo iban re-

\footnotetext{
14. Vega, Poesía selecta, pp. 606-607, 619-621. Sobre su condición de escritor madrileño, que él mismo revindicaría, remitimos a Carreira, 2010

15. Vélez de Guevara, El Diablo Cojuelo, p. 160

16. Quevedo, Poesía varia, pp. 426-431, 561

17. García-Mercadal, 1999, ad indicem. También, por su recopilación bibliográfica, ver Maqueda Abreu, 2005, pp. 11-35.

18. Deleito y Piñuela, 1988, pp. 30-39. En este mismo libro, el autor aporta jugosos comentarios sobre otras fiestas populares que tenían el río como escenario: el Ángel de la Guarda, San Isidro o San Juan Bautista. 19. Colección Abelló, 2014, pp. 163-164, núm. cat. 2.

20. Maravall, 2012, p. 388.

21. El precedente se encontraría en la obra de Liñán y Verdugo, Guía y avisos de forasteros... Recoge algunos testimonios literarios más Deleito, 1988, pp. 10-59.
} 
presentando papeles diferentes» ${ }^{22}$. Fue un escenario habitual de las celebraciones periódicas del calendario litúrgico, pero también de fiestas ocasionales -religiosas y profanas - en honor a personajes ilustres, como las que se organizaron durante la estancia, con tintes casi novelescos, del príncipe de Gales, en 1623. Interesa recordar ahora un episodio singular que aunaría pintura y espectáculo - de la soledad del creador a la exposición pública de su obra-, el que protagonizó Velázquez al pintar un Retrato ecuestre de Felipe IV que en 1626 «con su licencia y gusto se puso en la calle Mayor, enfrente de San Felipe, con la admiración de toda la corte e invidia de los de l'arte» 23; Francisco Pacheco, maestro y suegro del pintor, y Luis Vélez de Guevara dedicaron sendos sonetos al cuadro, hoy desaparecido, y Jerónimo González de Villanueva un extenso elogio poético.

Como hoy día, por ella se llegaba a la Puerta del Sol y, siguiendo la misma dirección, a la carrera de San Jerónimo, que moría en el Prado - Viejo de San Jerónimo y de Atocha-. Lugar a medio camino entre lo rural y lo urbano, estaba jalonado de huertas y prados por los que discurría el arroyo Abroñigal bajo. En este extremo oriental extramuros de la antigua Villa, desde 1503 se decidió erigir un monasterio de la Orden de San Jerónimo, ubicado en una elevación del terreno. Siguiendo la antigua tradición que vinculaba a los Trastámara con la Orden jerónima, la fundación gozó de la protección real desde sus inicios, y Felipe II construyó en torno a la cabecera de la iglesia el llamado Cuarto Real -iniciado en año crucial de 1561-, núcleo que daría origen al conjunto palatino erigido para Felipe IV. Además, a partir de la entrada en Madrid de Ana de Austria, en 1570, esta zona fue elegida para realizar los cortejos reales que ingresaban en la urbe ${ }^{24}$. Y en la iglesia de los Jerónimos se celebraron las juras de los Príncipes de Asturias desde el reinado de Felipe II hasta el de Isabel II25. A estos acontecimientos puntuales habría que sumar un sinfín de celebraciones religiosas y profanas que jalonaban el año y que tuvieron como escenario recurrente el Prado y su entorno.

Su primer momento de esplendor llegaría con la construcción del Palacio del Buen Retiro, impulsado por don Gaspar de Guzmán, conde-duque de Olivares, para retiro y solaz de Felipe IV. El conjunto se levantó en pocos años, aproximadamente entre 1630 y 1640, bajo la dirección de Giovanni Battista Crescenzi y, sobre todo, de Alonso de Carbonel, nombrado maestro mayor de sus obras en $1633^{26}$. Aquella feliz denominación ha pervivido en lo poco - y bueno- que se ha conservado de él: el Parque del Retiro. La conjunción entre arte y naturaleza sería uno de los rasgos definitorios del conjunto, conformado por una concatenación de construcciones y jardines; la Corte hallaba en él todo un universo de espacios diversos, obras artísticas, animales, plantas, fuentes, representaciones teatrales, tauromaquias, justas, juegos de pelota... para el Rey Planeta.

22. Vélez de Guevara, El Diablo Cojuelo, pp. 149 y 151.

23. Pacheco, El arte de la Pintura, p. 205. Sobre el retrato de Velázquez, Cruz Valdovinos, 2011, p. 78.

24. Cruz Valdovinos, 1990. Se puede comprobar este uso protocolario hasta el final del Barroco, reinan-

do Carlos II; Zapata Fernández de la Hoz, 1991.

25. Cámara Muñoz, 1986, p. 78; Portela Sandoval, 2006.

26. Sobre el proceso constructivo y la decoración interior del Palacio, resultan imprescindibles y recopilan la bibliografía anterior: El Palacio del Rey Planeta, 2005; Blanco Mozo, 2007. 
Así, en este otro extremo, relativamente alejado del Alcázar, se crearía un nuevo núcleo polarizador de la vida urbana. Un espacio que, con las transformaciones urbanísticas ordenadas por Carlos III, adquiriría un aspecto renovado a finales del siglo XVIII, revitalizando este espacio de sociabilidad fundamental para Madrid ${ }^{27}$. Quizá la representación pictórica más conocida del Buen Retiro, por su carácter totalizador y descriptivo, es la Vista del Palacio del Buen Retiro de Madrid, h. 16331637 (Patrimonio Nacional) atribuida a Jusepe Leonardo (fig. 3). Esta vista urbana - o suburbana, para ser precisos - es un alarde de perspectiva, pues ofrece una visión aérea - «a vuelo de pájaro»- imposible para la época, en la que el colosal Palacio está tratado como si fuera una maqueta a escala; en él se reconocen todas sus principales estructuras, delimitadas por la calle de Alcalá -con su antigua puerta - a un lado, una arboleda paralela al Prado de San Jerónimo, el monasterio jerónimo a otro y las tierras yermas y de labor que se pierden en el horizonte.

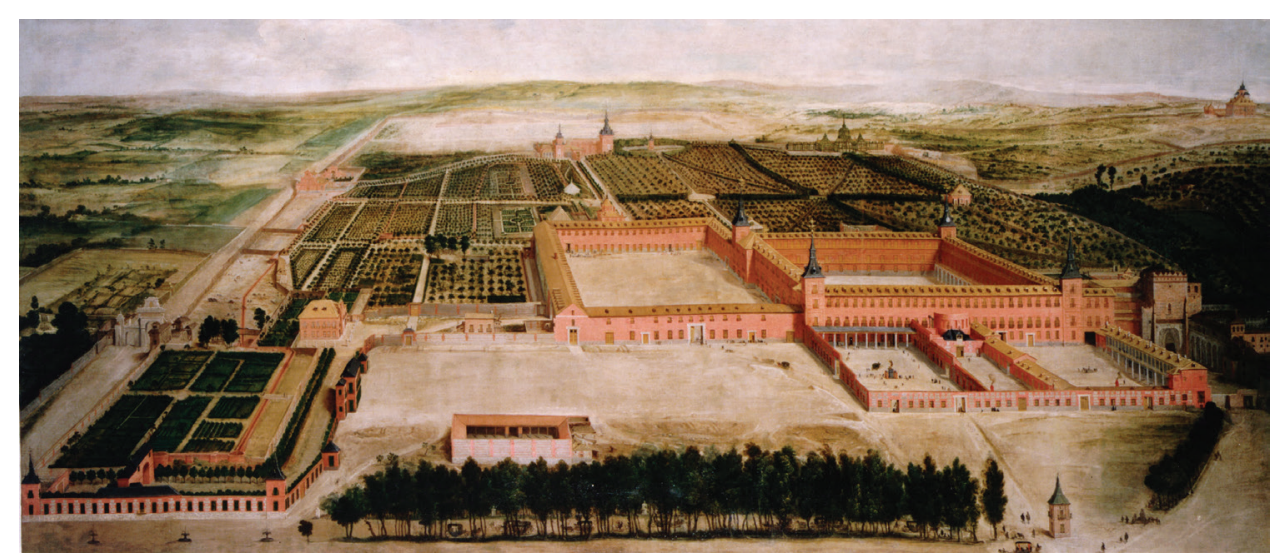

Fig. 3. Atribuido a Jusepe Leonardo. Vista del Palacio del Buen Retiro de Madrid, h. 1633-1637 (Patrimonio Nacional)

Tampoco se ha de olvidar de un lienzo singular de Diego Velázquez, La lección de justar del príncipe Baltasar Carlos, h. 1636-1638 (Colección del duque de Westminster, Londres). Es una obra ciertamente insólita en la producción de Velázquez, pues es la única, si exceptuamos los dos pequeños cuadritos que pintó en la Villa Medici (Museo del Prado, Madrid), en la que el artista representó el exterior de una arquitectura. Esta visión parcial del edificio se ha querido identificar con el ala sur del Buen Retiro, conocida como cuarto del Príncipe, situando la escena principal en el jardín de la Reina, si bien algunos autores discrepan ${ }^{28}$. 
Para la inauguración de la primera fase de sus obras, en 1633, Lope de Vega creó una comedia, añadiendo unos elogiosos «Versos a la primera fiesta del Palacio nuevo», que describió así:

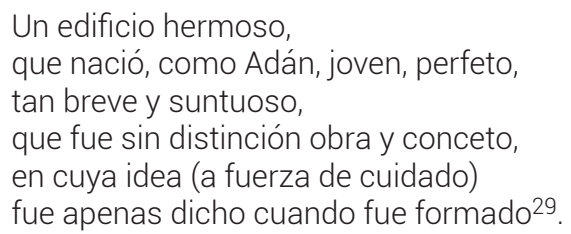

Asimismo, se publicaron Elogios al Palacio del Buen Retiro escritos por algunos ingenios de España... (Madrid, 1635), recogidos por don Diego de Covarrubias y Leyva, guarda mayor de este Real Sitio, y Obras varias al Real Palacio del Buen Retiro... (Madrid, 1637), del poeta Manoel de Galhegos. En 1637, la escritora Ana Caro de Mallén dedicó los siguientes versos a su plaza principal, trazada para satisfacer la megalomanía celebrativa del valido del Rey:

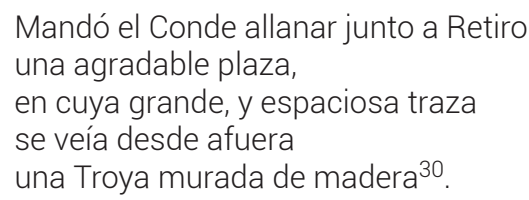

Fueron numerosas las representaciones teatrales que se sucedieron en el Buen Retiro a lo largo de media vida del Rey Planeta. Para la fiesta de la noche de San Juan de 1635, por ejemplo, el escenógrafo florentino Cosimo Lotti proyectó la obra de Calderón El mayor encanto, amor, dejando una valiosa descripción del artificio para el dramaturgo ${ }^{31}$. La construcción del Salón de baile -el Casón- (1637-1638) y, a continuación, del llamado Coliseo (1638-1640) brindaron espacios ad hoc para fiestas y representaciones, destacando los montajes de Lotti y de su sucesor, Baccio del Bianco, para diversas obras de Calderón. Pero, más allá del Coliseo y el Casón, el conjunto del Buen Retiro se transformaba en un inmenso escenario cortesano que desbordaba a menudo los límites entre la realidad y la ficción.

La construcción de este Palacio atrajo el interés de no pocos nobles y de altos funcionarios, que decidieron edificar sus casas suburbanas para estar cerca de la Corte, real y simbólicamente, en sus traslados al Buen Retiro. Aunque se ha de advertir que ya desde el último tercio del Quinientos, y en especial desde el regreso de la Corte en 1606 tras el paréntesis vallisoletano, el entorno del Prado Viejo experimentó un importante desarrollo urbanístico ${ }^{32}$. Quizá la más conocida y suntuosa fue la casa-jardín del duque de Lerma33, a la que siguieron otros personajes

29. Vega, La Vega del Parnaso, fol. 60v. Lo cita también Deleito, 2006, p. 214

30. Tomado de Blanco Mozo, 2007, p. 375.

31. Nieto Bedoya y Durán Cermeño, 1999, pp. 184-186; Arias de Cossío, 1999, pp. 204-206.

32. Lopezosa Aparicio, 2005, pp. 33-66; Muñoz de la Nava, 2016, pp. 399-411.

33. Ver nota antecedente. También Lopezosa Aparicio, 1998, pp. 457-485. 
eminentes como el marqués de Povar, el regidor Juan Fernández, el Almirante de Castilla o el conde de Monterrey. Para la casa-jardín de éste último, cuya entrada principal estaba situada en la calle del Árbol del Paraíso - nombre sugerente y muy oportuno-, Juan Silvestre Gómez escribió un panegírico titulado Jardín florido (1640). La composición funcionaba como un instrumento culto para reforzar el prestigio de su propietario - a quien se dedicó-; tras referirse largamente al jardín, con estos términos elogia la vivienda:

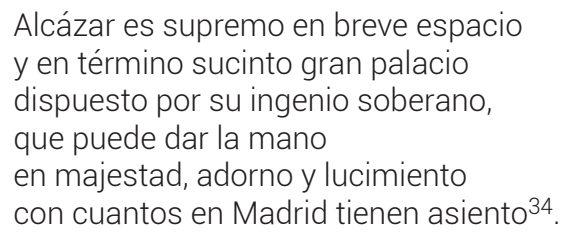

El conocimiento que tenemos de aquel palacio de los Monterrey a través de la composición de Silvestre y de la documentación se puede contrastar con los testimonios pintados que se conservan. Una pintura anónima que muestra una Vista del palacio del Buen Retiro, h. 1670 (Colección Abelló, Madrid) ${ }^{35}$, permite apreciar, en la parte inferior, el aspecto que tuvo el edificio, representado, asimismo, en la célebre Topographia de la Villa de Madrid realizada por Pedro de Texeira (1656). Recordemos, además, otras fuentes literarias que vienen a resaltar la importancia de este suntuoso enclave en la cultura festiva del círculo cortesano. En ausencia de sus propietarios - por hallarse en Nápoles como virreyes, entre 1628 y 1638-, doña Inés de Fonseca, hermana del conde de Monterrey, organizó junto a su esposo, el poderoso conde-duque de Olivares, diversas fiestas en aquel florido jardín. Sonada hubo de ser la que celebraran durante la noche de San Juan de 1631, a la que acudieron los Reyes, los infantes y lo más granado de la Corte; Francisco de Quevedo y Lope de Vega crearon sendas comedias para la ocasión, y Jerónimo Gascón de Torquemada escribió sobre «tan grandiosa y lucida» fiesta, de la que «salieron a las cinco de la mañana» ${ }^{36}$.

Pareja a la actividad edilicia en torno al Prado se tejerían, año tras año, una serie de usos y costumbres sociales en los que la carrera de San Jerónimo funcionaría como eje viario principal para conectar el casco antiguo de la ciudad con el emplazamiento cortesano. Los cortejos de carrozas de damas y caballeros engalanados y, a su alrededor, gentes de diversa condición (monjes, soldados, comerciantes, mozos, niños, mendigos...) afanados en sus cuitas y tareas cotidianas, tal y como muestra el lienzo atribuido a Jan van Kessel III, Vista de la carrera de San Jerónimo y el Paseo del Prado con cortejo de carrozas, 1686 (Museo Thyssen-Bornemisza, Madrid; fig. 4).

34. Ponce Cárdenas y Rivas Albadalejo, 2018, p. 225. En este trabajo se argumenta que «La Silva topográfica al Buen Retiro [de Manoel Galhegos] y el Jardín florido del conde de Monterrey son dos composiciones directamente interrelacionadas» (p. 197) 


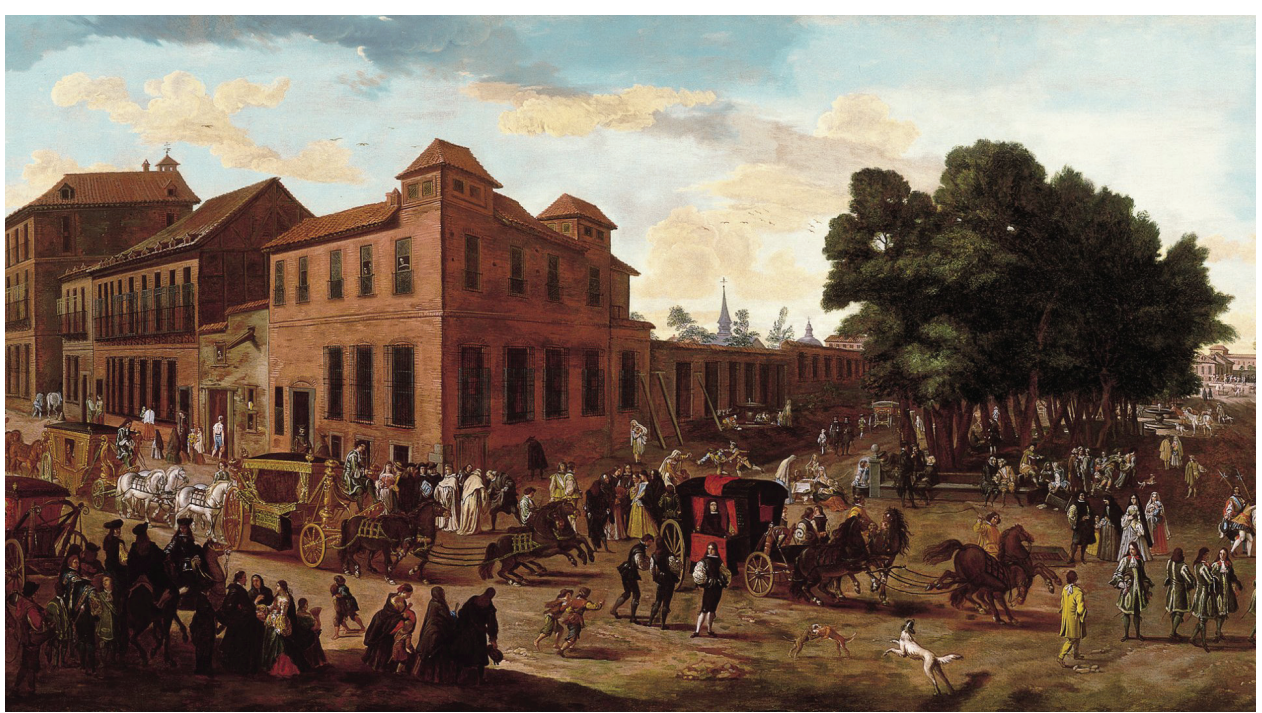

Fig. 4. Atribuido a Jan van Kessel III. Vista de la carrera de San Jerónimo y el Paseo del Prado con cortejo de carrozas, 1686

(Museo Thyssen-Bornemisza, Madrid)

Cinco décadas antes, Alonso de Castillo Solórzano había publicado Las harpías de Madrid y coche de las estafas (1631), colección de novelas cortas en la que sus protagonistas se movían en coche de caballos -objeto de elevado status social convertido en símbolo de vanidad y ostentación- por aquel escenario, y otros aledaños, de la Villa ${ }^{37}$. Tampoco se ha de olvidar el probable influjo de un precedente, El coche mendigón (1620), de Alonso Jerónimo de Salas Barbadillo38. Y en El Año Santo en Madrid (1650), auto sacramental de Pedro Calderón de la Barca, la Lascivia lleva al Hombre a contemplar las transeúntes de estas calles:

[...] en esta hermosa esfera de Calle Mayor y Prado en cuyo sitio ha llamado a Cortes la Primavera nos sentemos a mirar los que pasan $[\ldots]^{39}$. 
«Sólo Madrid es Corte», según la expresión, tantas veces repetida, de Alonso Núñez de Castro ${ }^{40}$. Y a mediados del siglo XVII, en el momento más floreciente de la cultura barroca hispánica, en pleno Siglo de Oro, esta afirmación fue más cierta que nunca. Las vistas urbanas que se pintaron, dibujaron y grabaron, junto a numerosos testimonios escritos conservados, ofrecen la imagen construida de una Corte en el tiempo en que su Imperio, poco a poco, se desmoronaba.

\subsection{Otros espacios de sociabilidad: la Plaza de la Villa y la Plaza Mayor}

Intramuros, los espacios más dilatados dentro de la morfología intrincada y sumamente abigarrada de la antigua Villa y Corte -recuérdense las llamadas «casas de malicia»-, eran fundamentalmente las plazas, cerradas por importantes edificaciones (del gobierno y la administración, iglesias, casas palaciegas) y ornamentadas con fuentes monumentales -Cervantes, por ejemplo, menciona cinco en la Segunda parte de El Quijote (1615) ${ }^{41}$ - . No sorprende, por tanto, que estos fueran puntos neurálgicos de vida social y que atrajeran la atención de algunos pintores, acaso especializados - con desigual fortuna- en estas vistas del interior de la urbe.

La teatralización del espacio urbano se convirtió en una constante de la Corte de los Austrias ${ }^{42}$. Las fiestas que se escenificaron constantemente en la ciudad - «cada día se ven en Madrid mil diversiones, ya en lo más levantado ya en lo inferior», escribió Jerónimo de Barrionuevo-, fueron manifestaciones características de la cultura barroca, producto expresivo de su mentalidad social y eficaz instrumento político, según explicara José A. Maravall/43.

Otro de los tópicos ligados a la villa castellana, popularizado con la conocida frase «De Madrid al cielo», encuentra su germen en la literatura del Siglo de Oro ${ }^{44}$. Cervantes, en El licenciado Vidriera (1613), dejó escrito: «- De Madrid, cielo y suelo; de Valladolid, los entresuelos» ${ }^{45}$. Suelo y cielo - lo lleno y lo vacío, lo vivido y lo anhelado- como espacios recurrentes en la construcción secular de la mirada, a la que han contribuido decisivamente la pintura y la literatura. Más claro y prolijo es el pasaje encomiástico que le dedicara María de Zayas en su novela Desengaños amorosos (1647), que subrayaba el carácter cosmopolita de la urbe:

40. Núñez de Castro, Libro histórico político. Sólo Madrid es Corte y el cortesano de Madrid (Madrid, 1658). 41. «[...] las fuentes de Leganitos y Lavapiés en Madrid, no olvidándome de la del Piojo, de la del Caño Dorado y de la Priora [...]» (Cervantes, Don Quijote de la Mancha, p. 718). Entre la producción cervantina, se hallan otras alusiones a Madrid en La Galatea, las Novelas ejemplares, el Viaje del Parnaso, Ocho comedias y ocho entremeses nuevos y Los trabajos de Persiles y Sigismunda.

42. Gállego, 1969; Cámara Muñoz, 2008.

43. Maravall, 2012, pp. 357-392. Ver también el clásico estudio de Orozco Díaz, 1969.

44. Sobre este asunto, remitimos al ensayo de Bonet Correa, 2004, p. 64.

45. Cervantes, Novelas ejemplares, p. 307. 
En la Babilonia de España; en la nueva maravilla de Europa; en la madre de la nobleza; en el jardín de los divinos entendimientos; en el amparo de todas las naciones; en la progenitora de la belleza; en el retrato de la gloria; en el archivo de todas las gracias; en la escuela de las ciencias; en el cielo tan parecido a Cielo, que es locura dejarle si no es para irse al Cielo, y, para decirlo todo de una vez, en la ilustre villa de Madrid, Babilonia, madre, maravilla, jardín, archivo, escuela, progenitora, retrato y cielo (en fin, retiro de todas las grandezas del mundo), nació la hermosísima Laurela ${ }^{46}$.

Volviendo a las imágenes pictóricas, el cuadro anónimo Milagro de la Virgen de Atocha en la construcción de la Casa de la Villa, 1675-1700 (Museo de la Ciudad de Madrid), es a un tiempo un documento excepcional para conocer la construcción de esta sede municipal -hasta 2007, sede principal del Ayuntamiento de Madridy su entorno urbano, observar aspectos sociales (estamentos reflejados en las vestimentas y en sus actividades, llegando incluso a lo anecdótico, como la riña entre caballeros) o constatar lo enraizado de unas creencias religiosas que atribuían la recurrente intervención milagrosa de determinadas advocaciones marianas (en este caso, la Virgen de Atocha, una de las que gozaron de mayor veneración y especial patrocinio regio). Además, en la pintura aparece la desaparecida fuente de San Salvador o de la Villa, realizada en 1620 por Antonio de Riera y Francisco según trazas del florentino Rutilio Gaci47.

Por supuesto, la Plaza Mayor - antigua Plaza del Arrabal - fue otro de esos puntos neurálgicos principales. Construida como tal en tiempos de Felipe III con trazas de Juan Gómez de Mora, corresponde a Felipe II el honor de haber impulsado la remodelación de este espacio emblemático, con la construcción de la Real Casa de la Panadería a cargo de Diego Sillero ${ }^{48}$. Dada su configuración y sus dimensiones, además de funcionar como mercado principal de la Villa, fue uno de los escenarios predilectos para la celebración de todo tipo de eventos públicos, en los que lo profano solían entreverarse, y a veces confundirse, con lo religioso: festividades del calendario litúrgico, como el Corpus Christi - para el que escribieron autos sacramentales Tirso de Molina, Lope de Vega o Calderón de la Barca-, canonizaciones, fiestas regias de diversa índole, entre otros, concitaron allí a la Villa y Corte.

Del siglo XVII se conservan diversos lienzos que muestran las celebraciones y espectáculos tan ligados al Barroco madrileño. Vistas de la Plaza Mayor de Madrid (Museo de la Ciudad de Madrid), obra anónima de h. 1620, muestra una comitiva regia y personajes de diversa condición (clérigos, frailes, damas, caballeros, comerciantes, mozos, etc.); en el ángulo superior izquierdo incluye el escudo de la Villa. Otro lienzo de autor desconocido, perteneciente al mismo Museo, representa la Fiesta en honor del cardenal Francesco Barberini, h. 1626, con diversas exhibi-

46. Zayas y Sotomayor, Desengaños amorosos, p. 577; el subrayado es nuestro. La imagen literaria de la Corte como Babilonia, en este caso interpretada con un sentido peyorativo, es analizada por Caporossi, 2004. 47. Las últimas aportaciones sobre esta obra, dentro de un interesantísimo estudio de las decoraciones efímeras en Madrid, en Zapata Fernández de la Hoz, 2016, pp. 300-303.

48. Remitimos al catálogo editado por la conmemoración de su IV Centenario: La Plaza Mayor. Retrato y máscara de Madrid, 2018. 
ciones a caballo. La estancia de este ilustre legado pontificio en la corte madrileña, entre mayo y agosto de aquel año, fue descrita en el diario de viaje de su secretario, el erudito y coleccionista Cassiano dal Pozzo ${ }^{49}$. Esta última representación pictórica tiene ciertos puntos en común con una pintura de Juan de la Corte ${ }^{50}$, h. 1623, del mismo Museo, donde se muestra otra exhibición del arte de justar y manejar la lanza, como los juegos de cañas que, junto a la anilla o el estafermo, se practicaban por entonces en la maestranza.

Asimismo, se organizaron numerosas fiestas taurinas, en especial durante el reinado de Felipe IV -Dal Pozzo describe una en honor al cardenal Barberini-, y así fueron plasmadas en diferentes lienzos anónimos de calidad mediocre: uno del Museo de la Ciudad de Madrid (h. 1664), dos de la Colección Abelló (h. 1675 y 1678)51, uno del Museo del Castello Sforzesco (Milán), uno del Museo alla Scala (Milán); además, en el patio del Castel Nuovo de Nápoles se conserva una pintura mural con el mismo tema. Estos festejos hallaron otros escenarios extramuros, según indicamos al referir la Vista de Madrid desde la salida del puente de Segovia con toros desmandados (h. 1640-1660), o en la explanada del Buen Retiro, donde se celebraron corridas de toros públicas y privadas ${ }^{52}$.

Resulta lógico que la visión en perspectiva elegida por los pintores del Barroco fuera siempre la que ofrecía la Casa de la Panadería como elemento central, a partir de cual se imponía la rigurosa simetría de la plaza. Aquella era la construcción más emblemática del conjunto, y, bajo sus decoraciones heráldicas -expresión perenne del poder de los monarcas - se situaba el balcón real, ocupado por la Real Familia cuando asistían a las celebraciones públicas.

Las palabras pintaron los que los pinceles describieron, $y$, de este modo, podemos recordar el pasaje escrito por Francisco de los Santos sobre una fiesta de toros en la Plaza Mayor:

Y habiendo Juanillo con el pincel del alma pintado el adorno real, sitio de los Católicos Reyes, pasando a los puestos de los Reales Consejos, lo pulido y compuesto de los balcones y ventanas, a quien adornan el oro de Arabia y el indiano metal gastado en vistosas y ricas colgaduras, la entrada de las Reales Guardias, el aire y gala con arrogante bizarría de la española nación, lo grave y majestuoso de la tropa alemana, lo riguroso y colérico de la nación tudesca, la entrada del Sol y Luna de España y el despojo de la plaza [...]. Viene por la mañana tanta gente al encierro de los toros que no queda lugar que no se ocupe. Córrense cuatro o seis de ellos y acábase la fiesta, y la gente que ocupaba los tablados se apea para cubrir la plaza 53 .

49. Simón Díaz, 1980; Dal Pozzo, Diario de viaje a España del Cardenal Francesco Barberini escrito por Cassiano dal Pozzo.

50. Es conocido que el flamenco Juan de la Corte fue un pintor especializado en «batallas, países y perspectivas» (Ceán Bermúdez, Diccionario histórico..., l, p. 365).

51. Colección Abelló, 2014, pp. 22-23 y 163-164, cat. núms. 1 y 3.

52. Deleito, 1988, pp. 103-104.

53. Santos, Día y noche de Madrid, pp. 158-159 
Finalmente, entre todas las representaciones de este espacio urbano, destaca por su calidad y morosidad descriptiva el Auto de fe en la Plaza Mayor de Madrid (Museo del Prado, Madrid) pintado en 1683 por Francisco Rizi (fig. 5). Aunque a nuestra mirada contemporánea nos resultan un horror aberrante, entonces los autos de fe promovidos por la Inquisición española formaban parte de los mecanismos coercitivos para mantener el statu quo del Antiguo Régimen, y, en su variante de espectáculo público, venían a ser una suerte de teatralización ritual del Juicio Final ${ }^{54}$. Sólo así se puede llegar a entender el encargo de una obra como ésta, ejecutada por el madrileño Francisco Rizi, pintor de Cámara de Carlos II, para inmortalizar aquella jornada. El 30 de junio de 1680 el Monarca presidió el auto general de fe de carácter público, algo que no acontecía en la ciudad desde el año 1632 y que, a la postre, sería el penúltimo (en 1720 Felipe $V$ presidió el último). El diseño arquitectónico de la Plaza Mayor y el tablado que se instaló para la ocasión refuerzan, en este caso, la solemnidad del acto55. En la pintura, por otra parte, queda patente la jerarquización de este espacio, expresión de una sociedad estamental que buscaba «reconocerse a sí misma, en sus jerarquías y en sus grados, viéndose en una casi infinita serie de fiestas y ceremonias que periódicamente y a lo largo del año re-presentaban la liturgia del orden plural que daba cuerpo a una comunidad» ${ }^{56}$.

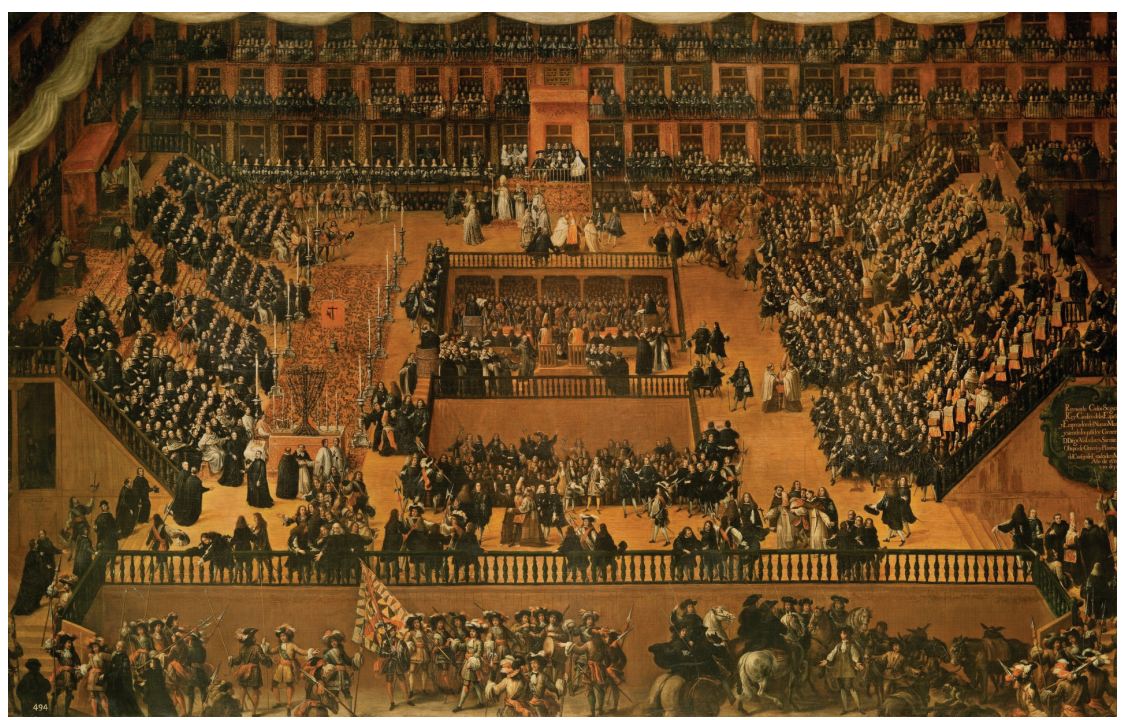

Fig. 5. Francisco Rizi. Auto de fe en la Plaza Mayor de Madrid, 1683 (Museo Nacional del Prado, Madrid)

54. Parello, 2011

55. Este tablado -o «teatro» - fue trazado por el maestro mayor de las Obras Reales y de la Villa de Madrid, José del Olmo, también alcaide y familiar del Santo Oficio y autor de la Relación histórica del auto general de fe que se celebró en la Plaza Mayor de Madrid en el año de 1680... (Madrid, 1680) escrita sobre el mencionado auto. Para ilustrar esta obra mediante la estampa, Gregorio Fosman y Medina abrió una lámina de cobre, adquirida en 2018 por el Museo del Prado; su composición serviría a Rizi para realizar la pintura aludida.

56. Bouza, 2020, p. 89. 
Al contemplar esta pintura monumental, y después de echar un vistazo general, uno siente la curiosidad de recorrer con los ojos la apariencia y las acciones de unos personajes que, como en El gran teatro del mundo (1655) de Calderón, representan su papel ante la mirada escrutadora del Dios en que creían. Incluso, se puede acertar a identificar a varios de ellos, como las inconfundibles figuras de la tríada regia en el balcón (Carlos II, María Luisa de Orleans y Mariana de Austria) o del $V$ duque de Pastrana, representado elegantemente pocos años antes, hacia 1679, por Juan Carreño de Miranda (Museo del Prado).

Teatro de las grandezas de la Villa de Madrid, Corte de los Reyes (1623); el elocuente título de Gil González Dávila, cronista de Felipe IV, condensa buena parte de las ideas que venimos comentando. La Corte de los Austrias convirtió a la antigua Villa en un verdadero theatrum mundi en el que se quiso proyectar la «cabeza del más estendido Imperio que ha tenido Rey del mundo» ${ }^{57}$, precisamente cuando este Imperio sufría síntomas inequívocos de su progresiva descomposición.

\section{CONCLUSIONES}

Tras este particular recorrido pictórico-literario, es fácil corroborar que existieron varios puntos neurálgicos de la vida madrileña aurisecular. El antiguo Alcázar y su proyección hacia el río Manzanares, el Palacio del Buen Retiro y el entorno del Prado, o la Plaza Mayor, convertidos en auténticos escenarios teatrales de aquella sociedad, hallaron su reflejo artístico en numerosas imágenes pintadas o escritas.

Artífices de la pintura y escritores escogieron estos lugares comunes, ofreciendo a la posteridad una visión fragmentaria y subjetiva, a veces sublimando la realidad, otras ridiculizándola. Sus creaciones, más o menos afortunadas, forman parte de nuestro acervo cultural, integran un patrimonio de extraordinario valor que es necesario conocer, estudiar, preservar y difundir.

La percepción actual de la ciudad histórica se fundamenta, en gran medida, sobre los cimientos culturales de aquel siglo áureo de la cultura hispánica -a su vez, erigidos sobre sus orígenes medievales, hoy apenas visibles-. Con el tiempo se fueron hibridando, solapando o imponiendo otros estratos, y, en torno a ellos, otras imágenes y escrituras pretéritas: las importantes transformaciones de los Borbones durante el siglo XVIII, las reformas y el crecimiento de la urbe en el siglo XIX, las cicatrices e intervenciones de la pasada centuria... Pero las huellas culturales de aquel brillante período, entre el Renacimiento y el Barroco, aún pueden rastrearse de manera muy enjundiosa a través del afortunado maridaje que ofrecen las fuentes literarias y artísticas de la época; y, por medio de la lectura crítica y atenta de estas obras, descifrar una parte primordial del formidable palimpsesto urbano que es Madrid.

57. González Dávila, Teatro de las grandezas de la Villa de Madrid, Corte de los reyes..., p. 1. 


\section{BiBLIOgRAFÍA}

Alvar Ezquerra, Alfredo, Felipe II, la Corte y Madrid en 1567, Madrid, CSIC, 1985.

Alvar Ezquerra, Alfredo, El nacimiento de una capital europea: Madrid entre 1561 y 1606, Madrid, Turner, 1989.

Arias de Cossío, Ana María, «Velázquez y el teatro», Madrid. Revista de Historia del Arte, Geografía e Historia, 2, 1999, pp. 195-215.

Baquero Escudero, Ana L., «La singularidad de Las harpías en Madrid de Castillo Solórzano», eHumanista, 38, 2018, pp. 519-536.

Blanco Mozo, Juan Luis, Alonso de Carbonel (1583-1660). Arquitecto del Rey y del Conde-Duque de Olivares, Madrid, FUE, 2007.

Bonet Correa, Antonio, «De la Villa y Corte a la metrópoli moderna: la imagen pictórica de Madrid», en Palabras pintadas. 70 miradas sobre Madrid, catálogo de la exposición, Madrid, Fundación Caja Madrid, 2004.

Bouza, Fernando, Palabra, imagen y mirada en la Corte del Siglo de Oro. Historia cultural de las prácticas orales y visuales de la nobleza, Madrid, Abada, 2020.

Cámara Muñoz, Alicia, «El poder de la imagen y la imagen del poder. La fiesta en Madrid en el Renacimiento», en Madrid en el Renacimiento, catálogo de la exposición, Madrid, Comunidad de Madrid, 1986, pp. 61-94.

Cámara Muñoz, Alicia, «La ciudad en la literatura del Siglo de Oro», Anales de Historia del Arte, vol. extra, 2008, pp. 121-133.

Caporossi, Olivier, «La Babilonia del crimen o la nueva Roma de la policía cristiana: el discurso sobre la decadencia y la reformación de la Corte en la primera mitad del siglo XVII (1597-1645)», en La declinación de la monarquía hispánica en el siglo XVII, coord. Francisco José Aranda Pérez, Cuenca, Universidad de Castilla-La Mancha, 2004, pp. 845-861.

Carreira, Antonio, «La Corte y sus ingenios», en Literatura y territorio. Hacia una geografía de la creación literaria en los Siglos de Oro, ed. Andrés Sánchez Robayna, Las Palmas de Gran Canaria, Academia Canaria de la Historia, 2010, pp. 59-72.

Ceán Bermúdez, Juan Agustín, Diccionario histórico de los más ilustres profesores de las Bellas Artes en España, Madrid, Viuda de Ibarra, 1800, 5 tomos y Apéndice.

Cervantes, Miguel de, Don Quijote de la Mancha, ed. Francisco Rico, Madrid, Alfaguara, 2007 [1605-1615].

Cervantes, Miguel de, Novelas ejemplares, Madrid, Espasa-Calpe, 1983 [1615].

Colección Abelló, catálogo de la exposición, Madrid, Ayuntamiento de Madrid, 2014.

Cruz Valdovinos, José Manuel, «La entrada de la reina Ana en Madrid. Estudio documental», Anales del Instituto de Estudios Madrileños, XXVIII, 1990, pp. 413-451. 
Cruz Valdovinos, José Manuel, Velázquez. Vida y obra de un pintor cortesano, Zaragoza, Caja Inmaculada, 2011.

Dal Pozzo, Cassiano, Diario de viaje a España del Cardenal Francesco Barberini escrito por Cassiano dal Pozzo, ed. Elisabet Roig Cañadas, Aranjuez, Doce Calles, 2004 [1626].

De Seta, Cesare, «Ritratti di città dal Rinascimento al XVIII secolo», en La cultura y la ciudad, ed. Juan Calatrava, Francisco García Pérez y David Arredondo Garrido, Granada, Editorial Universidad de Granada, 2016, pp. 1-12.

Deleito y Piñuela, José, ... también se divierte el pueblo, Madrid, Alianza, 1988.

Deleito y Piñuela, José, El rey se divierte, Madrid, Alianza, 2006.

El Palacio del Rey Planeta. Felipe IV y el Buen Retiro, catálogo de la exposición, Madrid, Museo Nacional del Prado, 2005.

El Real Alcázar de Madrid, catálogo de la exposición, Madrid, Nerea, 1994.

Galera i Monegal, Montserrat, Antoon van den Wijngaerde, pintor de ciudades y de hechos de armas en la Europa del Quinientos. Cartobibliografía razonada de los dibujos y grabados, y ensayo de reconstrucción documental de la obra pictórica, Barcelona, FCA-ICC, 1998.

Gállego, Julián, «El Madrid de los Austrias: un urbanismo de teatro», Revista de Occidente, 73, 1969, pp. 19-53.

García-Mercadal, José, Viajes de extranjeros por España y Portugal, Salamanca, Junta de Castilla y León, 1999, 6 tomos.

García Santo-Tomás, Enrique, Espacio urbano y creación literaria en el Madrid de Felipe IV, Madrid / Frankfurt am Main, Iberoamericana / Vervuert, 2004.

García Santo-Tomás, Enrique, Modernidad bajo sospecha, Madrid, CSIC, 2008.

Gerard, Veronique, De castillo a palacio. El Alcázar de Madrid en el siglo XVI, Bilbao, Xarait, 1984.

Góngora, Luis de, Poesía, ed. Ana Suárez Miramón, Barcelona, Debolsillo, 2002 [1609].

González Dávila, Gil, Teatro de las grandezas de la Villa de Madrid, Corte de los reyes..., Madrid, Tomás Junta, 1623.

La Plaza Mayor. Retrato y máscara de Madrid, catálogo de la exposición, Madrid, Ayuntamiento de Madrid, 2018.

Liñán y Verdugo, Antonio, Guía y avisos de forasteros, adonde se les enseña a huir de los peligros que hay en la vida de Corte..., Madrid, Viuda de Alonso Martín, 1620.

Lopezosa Aparicio, Concepción, «La residencia del Duque de Lerma en el Prado de San Jerónimo, traza de Gómez de Mora», Madrid. Revista de Arte, Geografía e Historia, 1, 1998, pp. 457-485. 
Lopezosa Aparicio, Concepción, El Paseo del Prado de Madrid: arquitectura y desarrollo urbano en los siglos XVII y XVIII, Madrid, FAHAH, 2005.

Lynch, Kevin, La imagen de la ciudad, Barcelona, Gustavo Gili, 2015 [1960].

Maqueda Abreu, Consuelo, «La corte española del Barroco vista por los extranjeros», Madrid. Revista de Historia del Arte, Geografía e Historia, 8, 2005, pp. 11-35.

Maravall, José Antonio, La cultura del Barroco. Análisis de una estructura histórica, Barcelona, Ariel, 2012 [1975].

Muñoz de la Nava Chacón, José Miguel, Espacios públicos de ocio en el Madrid de Felipe II y Felipe III, Tesis doctoral, Madrid, Universidad Complutense de Madrid, 2016.

Nieto Bedoya, Marta, y Durán Cermeño, Consuelo, «Escenografía, usos y maneras del rey Felipe IV y la Corte en el Real Sitio del Buen Retiro», Madrid. Revista de Historia del Arte, Geografía e Historia, 2, 1999, pp. 171-194.

Núñez de Castro, Alonso, Libro histórico político. Sólo Madrid es Corte y el cortesano de Madrid, Madrid, Andrés García de la Iglesia, 1658.

Olmo, José del, Relación histórica del auto general de fe que se celebró en la Plaza Mayor de Madrid en el año de 1680..., Madrid, Roque Rico de Miranda, 1680.

Orozco Díaz, Emilio, El teatro y la teatralización del Barroco (Ensayo de introducción al tema), Barcelona, Planeta, 1969.

Pacheco, Francisco, El arte de la Pintura, ed. Bonaventura Bassegoda, Madrid, Cátedra, 1990 [1649].

Parello, Vicent, «Una fiesta barroca en tiempos de Carlos II: el auto de fe madrileño de 1680», Les Cahiers de Framespa, 8, 2011, 15 pp., en <https://journals.openedition.org/framespa/794> [consulta el 31/03/2020].

Ponce Cárdenas, Jesús, y Rivas Albadalejo, Ángel, El jardín del Conde de Monterrey. Arte, naturaleza y panegírico, Salamanca, Delirio, 2018.

Portela Sandoval, Francisco José, «A propósito de la jura de los príncipes herederos: una nueva lectura del cuadro Jura de don Fernando (VII) como príncipe de Asturias, de Luis Paret», En la España medieval, Extra 1, 2006, pp. 337-348.

Quevedo, Francisco de, Poesía varia, ed. James O. Crosby, Madrid, Cátedra, 2005 [1648].

Remiro de Navarra, Baptista, Los peligros de Madrid, Zaragoza, Pedro Lanaja, 1646.

Río Barredo, María José del, Madrid, Urbs Regia. La capital ceremonial de la Monarquía Católica, Madrid, Marcial Pons, 2000.

Rodríguez Romero, Eva Juana (coord.), Paisajes de aproximación a la ciudad de Madrid, Madrid, Conarquitectura, 2018.

Rossi, Aldo, La arquitectura de la ciudad, Barcelona, Gustavo Gill, 2015 [1978]. 
Santos, Francisco, Día y noche de Madrid, ed. Enrique García Santo-Tomás, Madrid, Cátedra, 2016 [1663].

Simón Díaz, José, «La estancia de cardenal legado Francesco Barberini en Madrid en el año 1626», Anales del Instituto de Estudios Madrileños, XVII, 1980, pp. 159-213.

Val Moreno, Gloria del, Giovanni Battista Crescenzi (Roma, 1577-Madrid, 1635) y la renovación de las artes durante el reinado de Felipe IV, Tesis doctoral, Madrid, Universidad Complutense de Madrid, 2017.

Vega, Lope de, Poesía selecta, ed. Antonio Carreño, Madrid, Cátedra, 2017 [1634].

Vega, Lope de, La Vega del Parnaso, ed. Felipe B. Pedraza y Pedro Conde Parrado, Cuenca, Universidad de Castilla-La Mancha, 2015 [1637].

Vélez de Guevara, Luis, El Diablo Cojuelo, ed. Enrique Rodríguez Cepeda, Madrid, Cátedra, 2007 [1641].

Zapata Fernández de la Hoz, Teresa, Arquitecturas efímeras y festivas en la corte de Carlos II: las entradas reales, Madrid, Universidad Complutense de Madrid (tesis doctoral), 1991.

Zapata Fernández de la Hoz, Teresa, La Corte de Felipe IV se viste de fiesta. La entrada de Mariana de Austria (1649), Valencia, Universitat de València, 2016.

Zayas y Sotomayor, María de, Desengaños amorosos, ed. Julián Olivares, Madrid, Fundación José Antonio de Castro, 2001 [1647]. 